\title{
ARTIGO
}

DOI: https://doi.org/10.22481/praxis.v15i31.4675

\section{A POLÍTICA DE EDUCAÇÃO INTEGRAL EM TEMPO INTEGRAL: A PERSPECTIVA DOS PROFESSORES}

\author{
THE COMPREHENSIVE INTEGRAL EDUCATION POLICY: A TEACHER'S \\ PERSPECTIVE
}

\section{LA POLÍTICA DE EDUCACIÓN INTEGRAL EN TIEMPO INTEGRAL: LA PERSPECTIVA DE LOS PROFESSORES}

\author{
Tânia Castro Gomes \\ Universidade Federal do Oeste do Pará - Brasil \\ Maria Lília Imbiriba Sousa Colares \\ Universidade Federal do Oeste do Pará - Brasil
}

\begin{abstract}
Resumo: O presente artigo aborda a política e as experiências de educação integral em tempo integral no Brasil, tendo como recorte as experiências acontecidas na rede estadual de ensino no município de Santarém - Pará e discorre a partir da caraterização da escola e dos participantes da pesquisa sobre estas experiências na perspectiva dos professores relacionando sua prática pedagógica em sala de aula. Realizamos pesquisa empírica cujo instrumento foi o questionário e os itens foram organizados e sistematizados em gráficos e tabelas; a análise foi referendada em fontes bibliográficas e documentais (leis, decretos) que delineiam discussões sobre as políticas educacionais de educação integral. Os resultados deste estudo demonstram que é necessário conhecer a realidade das escolas que por sua diversidade, enfrenta desafios na efetivação da política educacional de educação integral em tempo integral como por exemplo: adequação de tempo, espaço, metodologias, formação e a prática pedagógica desenvolvida no cotidiano da escola.
\end{abstract}

Palavras-chave: Educação Integral; Tempo Integral; Prática Pedagógica.

\begin{abstract}
This article deals with the politics and experiences of full - time integral education in Brazil, having as a cut - off the experiences that took place in the state education network in the municipality of Santarém - Pará and discusses the characterization of the school and the participants of the research on these experiences from the perspective of teachers relating their pedagogical practice in the classroom. We performed empirical research whose instrument was the questionnaire and the items were organized and systematized in charts and tables; the analysis was based on bibliographical and documentary sources (laws, decrees) that delineated discussions on educational policies of integral education. The results of this study demonstrate that it is necessary to know the reality of the schools that, due to their diversity, face challenges in the implementation of the education policy of full time integral education such as: adequacy of time, space, methodologies, training and pedagogical practice developed in the of the school.
\end{abstract}

Key words: Integral Education; Full-Time; Pedagogical Practice. 
Resumem: El presente artículo aborda la política y las experiencias de educación integral a tiempo completo en Brasil, teniendo como recorte las experiencias ocurridas en la red estadual de enseñanza en el municipio de Santarém - Pará y discurre a partir de la caraterización de la escuela y de los participantes de la investigación sobre estas experiencias en la perspectiva de los profesores relacionando su práctica pedagógica en el aula. Realizamos investigación empírica cuyo instrumento fue el cuestionario y los ítems fueron organizados y sistematizados en gráficos y tablas; el análisis fue refrendado en fuentes bibliográficas y documentales (leyes, decretos) que delinean discusiones sobre las políticas educativas de educación integral. Los resultados de este estudio demuestran que es necesario conocer la realidad de las escuelas que por su diversidad enfrenta desafíos en la efectividad de la política educativa de educación integral a tiempo completo como por ejemplo: adecuación de tiempo, espacio, metodologías, formación y práctica pedagógica desarrollada de la escuela.

Palabras clave: Educación Integral; Tiempo Integral; Práctica Pedagógica.

\section{Introdução}

O Programa Nacional de Cooperação Acadêmica, desenvolvido por meio do Edital $\mathrm{N}^{\circ}$ 071/2013 PROCAD/CAPES, é uma parceria cujas intuições partícipes são: Proponente: Universidade Estadual de Campinas (UNICAMP); IES Associada I: Universidade Federal de Rondônia (UNIR) e IES Associada II: Universidade Federal do Oeste do Pará (UFOPA). A referida colaboração do PROCAD, dentre outras ações, realizou uma pesquisa de campo, coordenada pela UFOPA nas escolas públicas do município de Santarém - Pará assim como nos municípios ${ }^{1}$ adjacentes em que a mesma atua, com o intuito de mapear as experiências de educação integral em tempo integral seja no que se refere a ampliação da jornada escolar ou atividades complementares que busquem desenvolver esta política.

A pesquisa tem como objetivo geral analisar a experiência em educação integral em uma Escola Estadual de Ensino Fundamental e Médio da cidade de Santarém/PA a partir dos dados coletados em 2017. Vale ressaltar que nesse período os programas Mais Educação e Ensino Médio Inovador já haviam sido concluídos na referida escola, porém os participantes da pesquisa em um total de 18, desenvolveram ações educativas ou acompanharam o desdobramento dos mesmos no período de 2009 a 2016.

Para tanto, neste artigo, incialmente discutimos as recentes mudanças educacionais no Brasil em consonância com a política de educação integral seguindo-se de um breve resgate da educação integral no Brasil. Posteriormente, apresentamos a contextualização da

\footnotetext{
${ }^{1}$ A UFOPA por meio de seus campi está presente nos seguintes municípios do oeste do Pará: Alenquer, Itaituba, Juruti, Monte Alegre, Óbidos e Oriximiná (Disponível em: http://www.ufopa.edu.br/ufopa/institucional/sobre-aufopa/historico-e-localizacao/. Acesso em 01.08.2018)
} 
escola pesquisa, o perfil dos participantes da pesquisa e a perspectiva dos professores quanto a educação integral em tempo integral desenvolvida por meio dos programas no atendimento aos alunos. As considerações finais apontam contribuições possíveis que favoreçam a prática pedagógica da educação integral em tempo integral considerando o cotidiano das unidades escolares.

\section{A política de educação integral em tempo integral e as atuais mudanças educacionais}

Em 2016, em meio a uma crise política a então presidenta Dilma Vana Rousseff (Dilma Rousseff) que exerceu seu $1^{\circ}$ mandato em 01/01/2011 a 01/01/2015 (04 anos) sendo reeleita por meio de eleições em um processo democrático para o período de 01/01/2015 a 01/01/2019 foi afastada de seu cargo condenada em um processo de "impeachment" que resultou em seu afastamento ${ }^{2}$ definitivo. Com isso, seu segundo mandato foi interrompido em 31/08/2016 assumindo a presidência seu vice Michel Temer. Esse fato vem acrescido de reformas propostas pelo então presidente Michel Temer na reorganização econômica do estado brasileiro incluiu reformas educacionais tendo como "carro chefe" a reforma do ensino médio brasileiro.

A reforma do ensino médio, foi viabilizada e corroborada pela Medida Provisória 746/2016 de 22 de setembro de 2016 que propunha a Política de Fomento à Implementação de Escolas de Ensino Médio em Tempo Integral que em pouco tempo converteu-se na Lei $\mathrm{n}^{\circ}$ 13.415, de 16 de fevereiro de 2017. A referida Lei, instituiu a Política de Fomento à Implementação de Escolas de Ensino Médio em Tempo Integral. Em complemento a essa legislação no âmbito do ensino médio, em 13 de junho de 2017, a Portaria $n^{0}$ 727, estabelece novas diretrizes, novos parâmetros e critérios para o Programa de Fomento às Escolas de Ensino Médio em Tempo Integral - EMTI, em conformidade com a Lei $\mathrm{n}^{\circ} 13.415$, de 16 de fevereiro de 2017.

A reestruturação que se propunha especificamente ao ensino médio, afetou diretamente a política de educação integral que reformulou os programas de incentivo a educação integral em tempo integral desenvolvidos desde 2009 e a partir de 2016 sofreram alterações em suas propostas originais asseguradas por desdobramentos legais que ratificaram essas modificações. Assim, decorrentes dessas alterações os programas de fomento a política

\footnotetext{
${ }^{2}$ Ver Orso (2017), Saviani (2017), Sanfelice (2017) e Corrêa e Garcia (2018).
} 
de educação integral em tempo integral podemos observar no quadro 01 suas novas nomenclaturas bem como seu foco atual destinado ao ensino médio.

Quadro 01 - Programas de Fomento a Educação Integral após a Reforma Educacional em 2016.

\begin{tabular}{|l|l|l|l|}
\hline PROGRAMA & SIGLA & RESPALDO LEGAL & $\begin{array}{l}\text { NÍVEL DE } \\
\text { ENSINO NA } \\
\text { EDUCAÇÃO } \\
\text { BÁSICA }\end{array}$ \\
\hline Programa Novo Mais Educação & PNME & $\begin{array}{l}\text { Portaria MEC N }{ }^{\circ} 1.144 / 2016 . \\
\text { Resolução FNDE No 17/2017. }\end{array}$ & $\begin{array}{l}\text { Ensino } \\
\text { Fundamental }\end{array}$ \\
\hline $\begin{array}{l}\text { Programa Ensino Médio } \\
\text { Inovador }\end{array}$ & $\begin{array}{l}\text { ProEM } \\
\text { I }\end{array}$ & $\begin{array}{l}\text { Resolução FNDE n }{ }^{\circ} 4 \text { de } 25 \text { de outubro de } \\
2016 .\end{array}$ & Ensino Médio \\
\hline $\begin{array}{l}\text { Escolas de Ensino Médio em } \\
\text { Tempo Integral }\end{array}$ & EMTI & Portaria No 727 de 13 de junho de 2017. & Ensino Médio \\
\hline
\end{tabular}

Fonte: Elaborado pelas autoras (2017), tendo como referência a legislação sobre o PNME e ProEMI a partir de 2016.

Com a mudança, os programas foram reorganizados a partir de seus formatos anteriores. Dentre as principais mudanças, no PNME ressaltou-se a ênfase nas disciplinas de Matemática e Língua Portuguesa a partir de sua obrigatoriedade e determinação de maior carga horária no desenvolvimento das atividades complementares junto a seu público atendido no ensino fundamental.

Da mesma forma, no ProEMI, na elaboração desenvolvimento da Proposta de Redesenho Curricular, composta por cinco Campos de Integração Curricular (ações a serem desenvolvidas na escola junto aos alunos do ensino médio), ressaltou-se a obrigatoriedade de quatro campos e somente uma opção restante para a escolha da comunidade escolar.

No entanto, ressaltamos que o objetivo deste trabalho é analisar os impactos das experiências pedagógicas das políticas de educação integral no Oeste Paraense, tendo como recorte, uma escola pública estadual até o ano de 2016, ou seja, antes da reforma educacional porém, diante de todas as mudanças acontecidas em 2016, consideramos ser coerente contextualizar os programas desenvolvidos nos dias atuais.

\section{Percurso da educação integral: breves considerações}

As discussões relacionadas a Educação Integral no Brasil não são recentes. Desde 1930 o Manifesto dos Pioneiros (1932) além de outras reinvindicações, pleiteava o direito a educação integral, baseado nos princípios: da educação com função essencialmente política, 
escola única, laica, gratuita e obrigatória cujas propostas visavam atender a demanda $\begin{array}{lllll}\text { crescente } & \text { de } & \text { escolarização } & \text { da } & \text { classe }\end{array}$ (http://www.histedbr.fe.unicamp.br/revista/edicoes/22e/doc1_22e.pdf, 2/06/2018).

Provenientes dessas discussões temos no itinerário das experiências de educação integral no Brasil, a implementação de projetos como Centro Educacional Carneiro Ribeiro (CECR), os Centros Integrados de Atendimento à Criança (Ciacs), os Centros de Atenção Integral à Criança (Caics) dentre outras, que inicialmente apresentam um caráter assistencialista na qual a intencionalidade de se fazer educação integral em tempo integral estão relacionadas ao cuidado com os alunos de classe econômica baixa no sentido de ofertar além da instrução dos conteúdos escolares o suprimento das necessidades básicas dos mesmos. Essa concepção de escola em tempo integral, de acordo com Cavaliere (2007) propaga que:

A visão predominante, de cunho assistencialista, vê a escola de tempo integral como uma escola para os desprivilegiados, que deve suprir deficiências gerais da formação dos alunos; uma escola que substitui a família e onde o mais relevante não é o conhecimento e sim a ocupação do tempo e a socialização primária. Com frequência, utiliza-se o termo "atendimento". A escola não é o lugar do saber, do aprendizado, da cultura, mas um lugar onde as crianças das classes populares serão "atendidas" de forma semelhante aos "doentes" (2007, p. 1028 e 1029).

Por outro lado, concepção diferente vislumbra a educação integral enquanto formação integral do educando e considera que a mesma independente do aumento ou não da jornada escolar tem possibilidade de desenvolver-se quando assume outro caráter, ou seja, o caráter de progressão educacional em seus múltiplos aspectos incluindo o aspecto do cuidado em harmonia com o crescimento, o desenvolvimento e aprendizagem que de acordo com Guará (2006) deve abranger:

[...] atividade diversificadas, organizando-se a escola para dar, ao aluno, a oportunidade de uma escolarização formal ampliada por um conjunto de experiências esportivas, artísticas, recreativas ou temáticas, em complementação ao currículo escolar formal (2006, p. 18).

Assim, o foco da educação integral para a formação integral está predominantemente na qualidade da educação oferecida e não na ampliação do tempo como corrobora Gadotti (2009):

Não se trata apenas de estar na escola em horário integral, mas de ter a possibilidade de desenvolver todas as potencialidades humanas, que 
envolvam o corpo, a mente, a sociabilidade, a arte, a cultura, a dança, a música, o esporte o lazer, etc. (2009, p.98).

Fazendo parte de uma agenda de política de educação integral em tempo integral no Brasil, desde 2009, as escolas públicas tiveram a oportunidade de experimentar por meio de adesão voluntária, programas que instigam a educação integral por meio do tempo integral inicialmente com o formato de ampliação da jornada escolar mediante a implementação dos programas que apresentamos no quadro 02:

Quadro 02 - Programas de Fomento a Educação Integral antes da Reforma Educacional em 2016.

\begin{tabular}{|l|c|l|l|}
\hline \multicolumn{1}{|c|}{ PROGRAMA } & SIGLA & \multicolumn{1}{|c|}{ RESPALDO LEGAL } & \multicolumn{1}{c|}{$\begin{array}{c}\text { NíVEL DE ENSINO } \\
\text { NA EDUCAÇÃO } \\
\text { BÁSICA }\end{array}$} \\
\hline $\begin{array}{l}\text { Programa Mais } \\
\text { Educação }\end{array}$ & PME & $\begin{array}{l}\text { Portaria Interministerial } \mathrm{N}^{\circ} 17 / 2007 . \\
\text { Decreto } \mathrm{N}^{\circ} 7.083, \text { de } 27 \text { de janeiro de } \\
2010 .\end{array}$ & Ensino Fundamental \\
\hline $\begin{array}{l}\text { Programa Ensino } \\
\text { Médio Inovador }\end{array}$ & ProEMI & $\begin{array}{l}\text { Portaria } \mathrm{n}^{\circ} \text { 971, de } 09 \text { de outubro de } \\
2009 .\end{array}$ & Ensino Médio \\
\hline
\end{tabular}

Fonte: Elaborado pelas autoras (2017) a partir da legislação referente ao PME e ProEMI no período de 2009 e 2010.

Em Santarém, as escolas da rede pública estadual desde 2009 até o período de vigência dos programas em seu formato original que foi em 2015, foram contempladas a partir da adesão voluntária com os programas de fomento a educação integral tanto com o PME quanto pelo ProEMI em um número de 20 unidades escolares como mostra o quadro a seguir:

Quadro 03 - Relação das Escolas Estaduais de Ensino Fundamental e Médio no Município de Santarém/Pa contempladas com o Programa Mais Educação/PME e Programa Ensino Médio Inovador/ProEMI.

\begin{tabular}{|c|l|c|c|c|}
\hline $\mathrm{N}^{\circ}$ & \multicolumn{1}{|c|}{ ESCOLA } & BAIRRO & $\begin{array}{c}\text { PME } \\
\text { ano de } \\
\text { implantação) }\end{array}$ & $\begin{array}{c}\text { PROEMI } \\
\text { (ano de } \\
\text { implantação }\end{array}$ \\
\hline 01 & EEEFM ALM SOARES DUTRA & Caranazal & 2010 & 2013 \\
\hline 02 & $\begin{array}{l}\text { EEEFM ANTONIO BATISTA BELO DE } \\
\text { CARVALHO }\end{array}$ & Urumari & 2010 & 2014 \\
\hline 03 & EEEFM DOM TIAGO RYAN & Santarenzinho & 2010 & 2012 \\
\hline 04 & EEEFM FREI AMBROSIO & Central & 2010 & 2013 \\
\hline 05 & EEEFM FREI OTHMAR & Santíssimo & 2010 & 2013 \\
\hline 06 & EEEFM JADER FONTENELLE BARBALHO & Jaderlândia & 2009 & 2013 \\
\hline 07 & EEEFM JOSE DE ALENCAR & Aparecida & 2010 & 2013 \\
\hline 08 & EEEFM JULIA G PASSARINHO & Santíssimo & 2010 & 2013 \\
\hline
\end{tabular}




\begin{tabular}{|c|l|c|c|c|}
\hline 09 & EEEFM MADRE IMACULADA & Prainha & 2009 & 2012 \\
\hline 10 & $\begin{array}{l}\text { EEEFM MAESTRO WILSON DIAS DA } \\
\text { FONSECA }\end{array}$ & Nova República & 2009 & 2012 \\
\hline 11 & EEEFM NOSSA SENHORA DE APARECIDA & 2009 & 2012 \\
\hline 12 & $\begin{array}{l}\text { EEEFM OLINDO DO CARMO NEVES (FECHOU } \\
\text { 2015) }\end{array}$ & Nova República & 2010 & 2012 \\
\hline 13 & EEEFM PEDRO ALVARES CABRAL & Laguinho & 2010 & 2012 \\
\hline 14 & EEEFM PLACIDO DE CASTRO & Diamantino & 2010 & 2012 \\
\hline 15 & EEEFM PROF ALUISIO LOPES MARTINS & Diamantino & 2009 & 2012 \\
\hline 16 & EEEFM PROF. MARIA UCHOA MARTINS & Santana & 2010 & 2013 \\
\hline 17 & EEEFM PROF ROMANA TAVARES LEAL & Aeroporto Velho & 2010 & 2013 \\
\hline 18 & $\begin{array}{l}\text { EEEFM PROF TEREZINHA DE JESUS } \\
\text { RODRIGUES }\end{array}$ & Diamantino & 2010 & 2012 \\
\hline 19 & EEEFM RIO TAPAJOS & Matinha & 2010 & 2012 \\
\hline 20 & EEEFM SAO FELIPE & enaça & 2010 \\
\hline
\end{tabular}

Fonte: Elaborado pelas autoras (2017) a partir de Aguiar (2016) e das informações coletadas na $5^{\text {a }}$ URE/SEDUC (2017).

Bem como em 2009, ano implantação do Programa Mais Educação (PME) e 2012 início das atividades do Programa Ensino Médio Inovador (ProEMI a 5a Unidade Regional de Ensino ( $5^{\mathrm{a} U R E)}$, com sede no município de em Santarém atendia um número de 40 escolas distribuídas nos municípios de: Aveiro (01), Belterra (01), Mojuí do Campos (01) e Santarém (37). Das escolas atendidas em Santarém, 05 escolas em 2009, iniciaram o PME. Em 2012, 10 unidades escolares aderiram ao ProEMI. Os referidos, caracterizavam-se como programas indutores de educação integral em tempo integral fomentados pelo governo federal. Os dados iniciais nos mostram que a implementação dos programas PME e ProEMI aconteceram de maneira gradual e que nem todas as escolas pertencentes a rede pública estadual no município de Santarém/Pa fizeram na época sua adesão voluntária aos programas como ilustrado no quadro 03, pois até mesmo a adesão estava condicionada a indicação da Secretaria de Educação do Estado SEDUC. A escola pesquisada foi contemplada com o PME e com o ProEMI nesse período em que a política foi executada (2009 a 2015) antes da reforma educacional que aconteceu em 2016.

\section{Contextualização da escola pesquisada}

De acordo com o Projeto Político Pedagógico (2018-2020), a Escola foi criada por meio do Decreto Municipal № 670, de 14 de março de 1984, sancionado pelo no primeiro 
mandato do prefeito Dr. Ronan Manuel Liberal Lira ${ }^{3}$ e foi inaugurada em 04 de setembro de 1984. A partir de janeiro de 1986, a escola migrou do sistema municipal para o sistema estadual de educação, através de acordo de comodato entre a Prefeitura Municipal de Santarém na gestão do prefeito José Ronaldo Campos de Sousa ${ }^{4}$, e o Governo do Estado do Pará, na administração do governador Jader Fontenelle Barbalho ${ }^{5}$.

No decorrer do desenvolvimento das atividades educacionais, vários anexos foram sendo agregados em virtude da demanda discente em bairros ou locais do planalto santareno considerados áreas rurais em que não havia oferta de ensino médio por parte da rede estadual de ensino. Em 1994, um anexo que funcionou na Escola do Serviço Social da Indústria (SESI) até 1999; na comunidade de Mararu (anexo I), funcionando na Escola Municipal Nazaré Demétrio Mussi, o Ensino Médio Regular, em 1997; na comunidade de Jacamim (anexo II), o Ensino Médio Regular e a modalidade Educação de Jovens e Adultos (EJA) em 1999, funcionando na Escola Municipal Santo Antônio, apenas no turno noturno.

Em 2014, em parceria com a Secretaria Municipal de Educação e Desporto (SEMED), o anexo II passou a funcionar, também, no turno vespertino, na Escola Municipal Professora Francisca Eliete da Costa Muniz. Sobre sua estrutura, Gomes e Colares nos esclarece que:

\footnotetext{
Quanto a seu aspecto físico, a escola é considerada, pela $5^{a}$ URE, de grande porte não somente pela quantidade de alunos que atende, mas também pela quantidade de dependências assim distribuídas: secretaria, sala de arquivo, sala da direção, sala da coordenação pedagógica, sala de professores, sala de multimeios, sala de leitura, sala de informática, sala multidisciplinar, cozinha, banheiros masculinos e femininos, área coberta, quadra esportiva, sala de atendimento educacional especializado (Educação Especial) e rádio escolar. Quanto às salas de aula, a escola possui 19 unidades e, em 2017, funcionam 11 salas no turno da manhã, que inicia às $7 \mathrm{~h} 30 \mathrm{~m}$ e encerra às $12 \mathrm{~h}, 08$ no turno da tarde que funciona no período de $13 \mathrm{~h} 30 \mathrm{~m}$ às $18 \mathrm{~h} 10 \mathrm{~m}$, e 07 no tuno da noite que vai de $19 \mathrm{~h} 15 \mathrm{~m}$ às $22 \mathrm{~h} 50 \mathrm{~m}$.

A escola atualmente oferece os seguintes níveis de ensino: Ensino Fundamental Maior ( $6^{\circ}$ ao $9^{\circ}$ ano); Ensino Médio ( $1^{\text {a }}$ a $3^{\text {a }}$ série); Ensino Médio Supletivo ( $1^{\mathrm{a}}$ e $2^{\mathrm{a}}$ Etapas), atendendo na sede um total de 786 alunos. Dispõe ainda de turmas em anexos (autorizados à implantação em 1994), localizadas em escolas na região do planalto santareno, que atendem alunos do Ensino Médio Regular ( $1^{\mathrm{a}}$ a $3^{\mathrm{a}}$ série) e da Educação de Jovens e Adultos (EJA), em um total de 302 alunos. Os alunos da sede e dos anexos perfazem um total geral de 1.088 no ano de 2017 (2018, p.97-98).
}

\footnotetext{
${ }^{3}$ Mandato correspondente ao período de 1981 - 1985.

${ }^{4}$ Mandato correspondente ao período de 1986 - 1988.

${ }^{5}$ Mandato correspondente ao período de $1983-1987$.
} 
Com relação aos programas: PME e ProEMI, a escola participou tanto do PME, referente ao ensino fundamental quanto do ProEMI que atendeu o ensino médio no que diz respeito ao desenvolvimento de atividades complementares no sentido de contemplar a educação integral em tempo integral em uma jornada ampliada ofertada aos alunos.

A escola pesquisada foi contemplada somente em 2010 com o PME e com o ProEMI nos anos de 2012, 2013, 2014 e 2015, sendo que iniciou sua execução partir 2013 em decorrência da organização e recebimento de recursos.

\section{Perfil dos participantes da pesquisa}

Dentre os 18 participantes da pesquisa, tivemos 01 gestor, 01 coordenador pedagógico, 01 assistente administrativo e 15 professores, sujeitos que participam efetivamente no dia a dia da comunidade escolar.

Inicialmente na Tabela 1 apresentamos o perfil de todos os participantes da pesquisa para que possamos/ou pudéssemos ter uma visão geral destes partícipes. No entanto, ressaltamos que no decorrer do desenvolvimento do artigo, de acordo com o enfoque do trabalho que são as práticas pedagógicas docentes, a análise é realizada sob a perspectiva dos professores que são em um número de 15 participantes. Por isso, a divergência inicial entre o número total dos entrevistados (18) e o número somente dos professores (15).

Retomando o total de pesquisados, a maioria (61\%) pertencem ao gênero feminino, assim como $56 \%$ na faixa etária compreendida entre 40 e 60 anos o que pressupõe uma experiência considerável quando cruzamos os dados como o tempo de trabalho na escola em que $28 \%$ dos entrevistados possuem entre 07 e 10 anos de atividades profissionais período em está incluso no recorte temporal em que os programas foram executados.

Quando nos atentamos para a formação acadêmica destes profissionais, o número de profissionais com pós-graduação lato sensu é expressivo (44\%). Em correspondência, a participação em formação diversa nos últimos três anos do total dos pesquisados chega a 83\% cuja utilização na prática profissional abrange $78 \%$ em contraposição a $22 \%$ que utilização os conhecimentos das formações eventualmente.

Tabela 1 - Perfil dos Participantes da Pesquisa

\begin{tabular}{|c|c|}
\hline \multicolumn{2}{|c|}{ Participantes da Pesquisa (N=18) } \\
\hline GÊNERO & \% \\
\hline Masculino & 39 \\
\hline Feminino & 61 \\
\hline
\end{tabular}




\begin{tabular}{|c|c|}
\hline FAIXA ETÁRIA & $\%$ \\
\hline Menos de 20 anos & 0 \\
\hline $20-40$ & 44 \\
\hline $40-60$ & 56 \\
\hline Mais de 60 & $\mathbf{0}$ \\
\hline ESCOLARIDADE & $\%$ \\
\hline Ensino Médio & 6 \\
\hline Superior Completo & 28 \\
\hline Pós Graduação lato sensu & 44 \\
\hline Pós Graduação stricto sensu & 22 \\
\hline TEMPO DE TRABALHO NA ESCOLA & $\%$ \\
\hline Menos de 01 ano & 0 \\
\hline 01-07 & 28 \\
\hline $07-10$ & 28 \\
\hline $10-15$ & 22 \\
\hline Mais de 15 & 22 \\
\hline PARTICIPAÇÃO EM FORMAÇÃO NOS ÚLTIMOS 03 ANOS & $\%$ \\
\hline Sim & 83 \\
\hline Não & 17 \\
\hline $\begin{array}{l}\text { UTILIZAÇÃO DOS CONHECIMENTOS DA FORMAÇÃO NA PRÁTICA } \\
\text { ESCOLAR }\end{array}$ & $\%$ \\
\hline Quase sempre & 78 \\
\hline Quase nunca & 0 \\
\hline Eventualmente (às vezes) & 22 \\
\hline Nunca & 0 \\
\hline
\end{tabular}

Fonte: elaborado pelas autoras (2018) a partir dos dados da pesquisa coletados na escola (2017).

No panorama apresentado, inferimos que dentre os profissionais que atuam na escola, contamos com professores que possuem o conhecimento prático/empírico das experiências vivenciadas no dia a dia da instituição escolar assim como o conhecimento teórico/técnico fundamentado na formação acadêmica e na formação continuada que visa aprimorar a prática educativa buscando o equilíbrio necessário a fundamentação teórica da prática em sala de aula. Seu papel é de estrema responsabilidade na condução do processo ensino aprendizagem pois está diretamente ligado a apropriação do conhecimento por parte do aluno. Neste sentido Orso destaca que o professor:

[...] por intermédio do trabalho que realiza, contribui para a compreensão da sociedade e superação de sua própria condição social, assim como, do conjunto da classe trabalhadora.

Enfim, o professor é um trabalhador como membro da mesma classe, com a "missão" de, por intermédio do trabalho que realiza, contribuir para a compreensão da sociedade e superação de sua própria condição social, assim como, do conjunto da classe trabalhadora (2008, p. 3852). 
Concordamos com Orso no que diz respeito a responsabilidade do professor na condução do processo ensino aprendizagem, pois, embora saibamos que existem vários aspectos relacionados a apropriação de conhecimentos que influenciam esse decurso como por exemplo, infraestrutura, organização pedagógica e a própria gestão, é o professor quem atua diretamente com o educando em sala de aula.

\section{A educação integral em tempo integral na perspectiva dos professores}

Vale ressaltar que a escola pesquisada, mesmo desenvolvendo programas que fomentam a educação integral em tempo integral, não alterou seu tempo de funcionamento e continuou com a organização do tempo parcial o que podemos confirmar com sua ordenação diária com turmas nos turnos: manhã, tarde e noite. Assim também como seus professores que ministravam normalmente suas atividades docentes com carga horária em sala de aula e participavam da organização e planejamento das ações do PME e ProEMI. No caso do PME as atividades que eram desenvolvidas por "terceiros" que não faziam parte do quadro da escola eram denominados "oficineiros" e no ProEMI tinham a frente os professores coordenadores dos projetos com o apoio de assessorias externas ${ }^{6}$ quando necessário em alguma temática específica.

Quanto aos professores entrevistados, foram em um total de quinze dos quais observamos de modo sintético no quadro 04 que, a maioria dos entrevistados (08) trabalham em três turnos diários: manhã, tarde noite em até três ou mais escolas sendo que a maioria também (07) trabalha somente na escola pesquisada. É possível também observar que na mesma escola onde foi realizado o trabalho, tem 08 professores com 40 horas semanais o que corresponde ao trabalho em dois turnos e 01 professor com mais de 40 horas semanais o que nos permite dizer que 9 dos 15 professores entrevistados estão na escola em três turnos e acompanham além da docência, a sua rotina de funcionamento.

Quadro 03 - Turnos, quantidades de escolas trabalhadas e carga horária semanal dos professores entrevistados.

\begin{tabular}{|l|l|c|}
\hline \multicolumn{1}{|c|}{ Questão } & \multicolumn{1}{|c|}{$\begin{array}{l}\text { Opções de } \\
\text { Respostas }\end{array}$} & No de Respostas $^{\text {Res }}$ \\
\hline Turnos que trabalha na educação & Manhã & 01 \\
\hline
\end{tabular}

\footnotetext{
${ }^{6}$ Palestrantes contratados por meio de consultorias habilitadas a expedir notas fiscais exigidas no processo de prestação de contas dos recursos utilizados nas atividades desenvolvidas.
} 


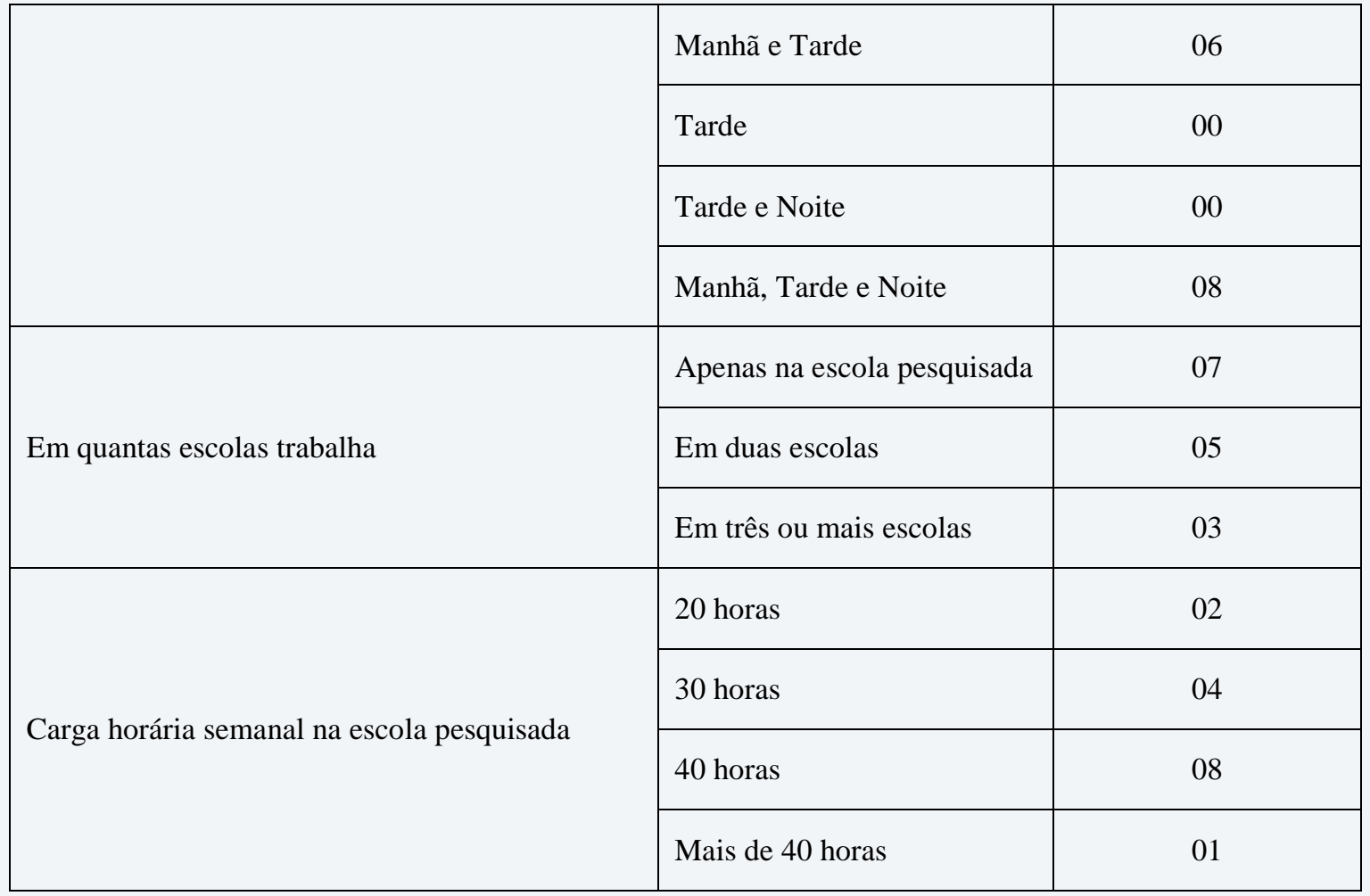

Fonte: elaborado pelas autoras (2018) a partir dos dados da pesquisa coletados na escola (2017).

Quanto à questão de relacionar o trabalho de sala de aula com outros espaços e/ou ambientes escolares, no próprio turno ou contraturno ou vivências extraescolares, quando perguntados sobre com quais atividades os professores associavam o seu trabalho de sala de aula, a maioria (40\%) respondeu dentre as alternativas previstas no instrumento da pesquisa responderam que conjugam a sala de aula com vivências extra escolares, trazendo para a sala de aula discussões referentes ao dia a dia dos alunos, enquanto que em um outro extremo, a minoria (13\%) conjuga as atividades de sala de aula com mais de dois ambientes educativos, que na escola tem como opção o laboratório de informática e o laboratório multidisciplinar bem como ações desenvolvidas nos projetos de ação que a escola efetiva durante o ano letivo.

Outro fato que podemos observar são os professores (27\%) que trabalham somente em sala de aula desenvolvendo os conteúdos necessários ao público atendido em cada série. Destes $27 \%, 75 \%$ afirmam que para conjugar o trabalho de sala de aula com outras atividades relacionadas ao ensino, necessitam de melhorias nas condições de trabalho enquanto que $25 \%$ afirmam estarem satisfeitas somente em desenvolver o trabalho dentro da sala de aula. Sobre a estrutura necessária ao desenvolvimento da docência, Maurício nos convida a ponderação de que:

É necessário tempo para adquirir hábitos, valores, conhecimentos para o exercício da cidadania numa sociedade complexa como a brasileira do 
Século XXI. Ninguém adquire hábitos de higiene sem praticar: é necessário tempo para escovar os dentes; é necessário tempo para fazer leituras críticas das imagens veiculadas pela televisão; é necessário tempo para praticar valores democráticos, na educação física, na hora da refeição, nas discussões em sala de aula (2013, p. 55).

Faz-se necessária a reflexão de que apesar de não ser determinante para realizar a docência, a falta de estrutura pode vir a ser um problema no desenvolvimento de atividades atrativas que "seduzam" o aluno na busca dos conhecimentos sólidos necessários à sua formação integral pois somente a utilização do espaço da sala de aula pode vir a tonar-se fatigante considerando em média quatro horas efetivas de trabalho com os alunos por turno.

Sobre os que conjugam as atividades de sala de aula com o contraturno no qual a princípio estariam sendo desenvolvidas ações relacionadas aos programas que fomentam a educação integral, nenhum professor, dos entrevistados, relacionou seu trabalho com o contraturno. Os dados acima descritos, podemos notar na figura 01:

Figura 01 - Sobre conjugar a prática da sala de aula e demais atividades escolares.

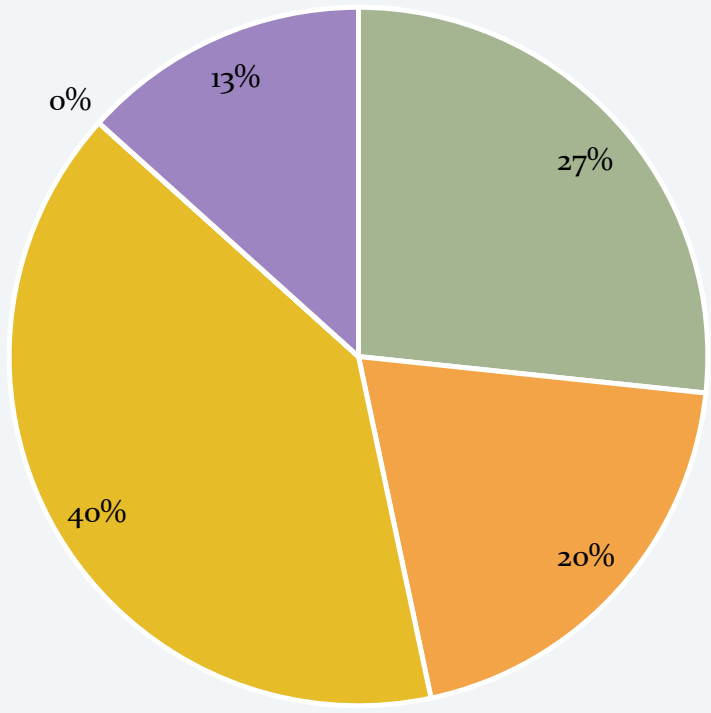

- a) Não conjugo. Trabalho apenas na sala de aula.

- b) Conjugo sala de aula e laboratório

- c) Conjugo sala de aula e vivências extraescolares.

- d) Conjugo sala de aula com as atividades do contraturno.

- e) Conjugo mais de dois ambientes educativos.

Fonte: elaborado pelas autoras (2018) a partir dos dados da pesquisa coletados na escola (2017).

Quando nos referimos ao objetivo da metodologia de ensino utilizada pelo $\mathrm{s}$ professores, podemos observar na figura 02 , o percentual das respostas obtidas: 
Figura 02 - Objetivo da metodologia de ensino utilizada.

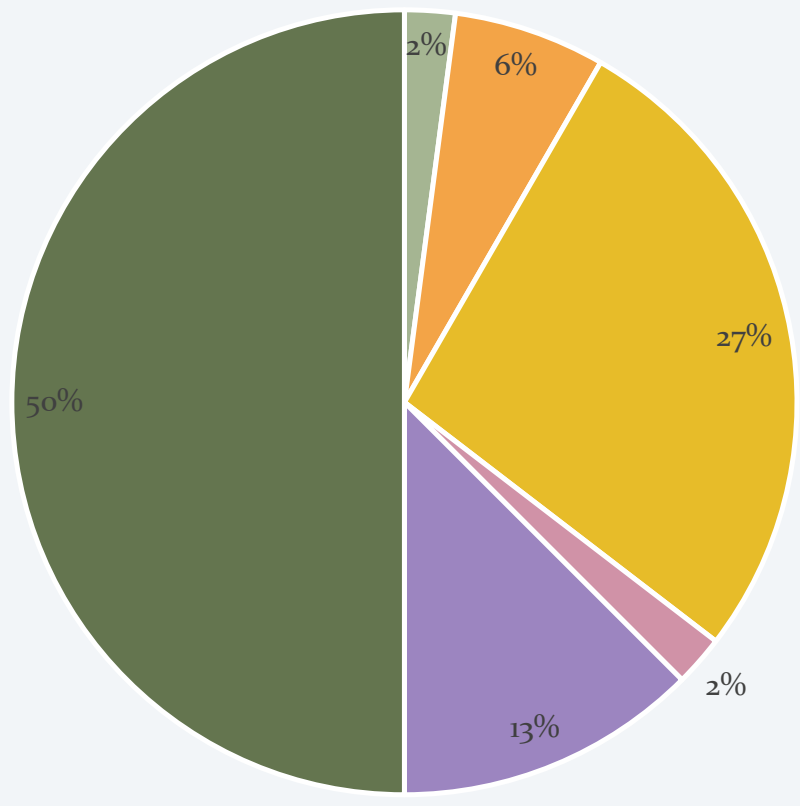

- a) Aprenda conteúdos.

• b) Desenvolva habilidades.

- c) Aprenda conteúdos e desenvolva habilidades.

- d) Aprenda conteúdos e desenvolva o gosto pelas artes.

- e) Aprenda conteúdos e se prepare para o trabalho

- Total de entrevistados

Fonte: elaborado pelas autoras (2018) a partir dos dados da pesquisa coletados na escola (2017).

Vale ressaltar, que os entrevistados poderiam escolher mais de uma opção, então, dentre as respostas dos professores temos em ordem decrescente, como objetivos da metodologia que o mesmo utiliza em sala de aula, $27 \%$ dizem que a metodologia tem como objetivo fazer com que o aluno aprenda os conteúdos e desenvolva habilidades; $13 \%$ para que o aluno aprenda o conteúdo e se prepare para o trabalho; 6\% somente desenvolver habilidades; $2 \%$ aprender os conteúdos e outros $2 \%$ aprender os conteúdos e desenvolver o gosto pelas artes.

Ainda sobre as características metodológicas, porém sob o enfoque da prática pedagógica temos os seguintes resultados apresentados na tabela 2:

Tabela 2 - Metodologia/Prática Docente

\begin{tabular}{|l|c|}
\hline \multicolumn{2}{|c|}{ Participantes da Pesquisa (N=15) } \\
\hline SUA METODOLOGIA DE ENSINO VISA FAZER COM QUE O ALUNO & $\%$ \\
\hline Desenvolva a cidadania. & 0 \\
\hline Desenvolva a cidadania participativa. & 53 \\
\hline Desenvolva a cidadania crítica. & 47 \\
\hline $\begin{array}{l}\text { INTERCALA AULA EXPOSITIVA, TRABALHO INDIVIDUAL, TRABALHO EM } \\
\text { GRUPO E DEBATES? }\end{array}$ & $\%$ \\
\hline Semanalmente & 21 \\
\hline Duas vezes por mês & 36 \\
\hline
\end{tabular}




\begin{tabular}{|l|c|}
\hline Uma vez por mês & 43 \\
\hline Nunca & 0 \\
\hline FAZ EXERCíCIOS, RELACIONANDO-OS COM TEXTOS DE JORNAIS, & $\%$ \\
REVISTAS OU SITES NA INTERNET? & 34 \\
\hline Semanalmente & 20 \\
\hline Duas vezes por mês & 33 \\
\hline Uma vez por mês & 13 \\
\hline Nunca & \\
\hline
\end{tabular}

Fonte: elaborado pelas autoras (2018) a partir dos dados da pesquisa coletados na escola(2017).

Enquanto características metodológicas apresentadas sobre a intenção do uso de determinada metodologia junto aos alunos, os entrevistados se dividem em: desenvolver cidadania participativa e crítica distintamente, sendo que de maneira geral percebemos que apesar do PPP enfocar o desenvolvimento do sujeito crítico participativo, enquanto algo indissociável, nas respostas mostradas no quadro acima observamos que os professores acreditam ser possível essa distinção.

Se existe a intencionalidade na utilização de determinada metodologia ou não para desenvolver o aluno seja crítico seja participativo, quando cruzamos essas informações com o método didático utilizado, percebemos um discurso incoerente com a prática pois, somente $21 \%$ dos professores intercalam a aula expositiva com trabalhos individuais em grupos ou debates, ou seja, 43\% utiliza aula expositiva que é uma das principais metodologias da pedagogia tradicional onde "a escola organiza-se como uma agência centrada no professor, o qual transmite, segundo uma gradação lógica, o acervo cultural aos alunos. A estes cabe assimilar os conhecimentos que lhes são transmitidos" (SAVIANI, 2008, p.6). Assim, o professor é o principal agente no processo de ensino aprendizagem deixando o aluno em segundo plano ao qual tem o papel de acatar o conhecimento repassado sem no entanto assumir o papel de sujeito nessa construção. Mantém uma postura passiva e de submissão, caso contrário é considerado indisciplinado.

No que se refere a exercícios que relacionam os conteúdos definidos no plano de curso com gêneros textuais estão inclusos jornais, revistas ou sites na internet, $34 \%$ dos professores informaram que realizam atividades que relacionam sim conteúdo com textos que permitam a compreensão prática dos mesmos permitindo assim, o desenvolvimento da habilidade de entender e refletir sobre o assunto trabalhado em sala de aula relacionando-os com a realidade em que o mesmo está situado por meio de informações que acontecem diariamente na sociedade. 
No entanto, $13 \%$ desses professores afirmaram na pesquisa que nunca utilizaram este tipo de atividade. Por mais que se configure em uma minoria, corrobora a percepção de que a pedagogia tradicional ainda é presente em nossas instituições escolares, colaborando para a manutenção da sociedade classista em que vivemos, pois de acordo com análise de Orso temos:

Todavia, no geral, predomina um tipo de educação abstrata, necessária à essa sociedade, pois, sendo determinante maior a base material, ela condiciona a consciência estabelecendo-se assim um tipo de educação correspondente a ela. Ou seja, uma educação voltada para estimular o individualismo, para fomentar a competição, para enaltecer a concorrência, para premiar pela 'produtividade e punir pelos resultados não desejados, permitindo, assim, selecionar os mais aptos e os mais adaptados, de acordo com os valores vigentes nessa sociedade - uma educação para subserviência. (2008, p.3843).

Diante das características apresentadas na prática pedagógica do professor em sala de aula outra temática apresentada que vem como consequência direta deste trabalho desenvolvido no cotidiano com os alunos são os possíveis problemas apresentados na apropriação desses conteúdos/conhecimentos que são dispostos por meio das metodologias acima discutidas. A frequência das respostas podem ser visualizadas na figura 03 a seguir:

Figura 03 - Sobre as causas dos problemas de aprendizagem.

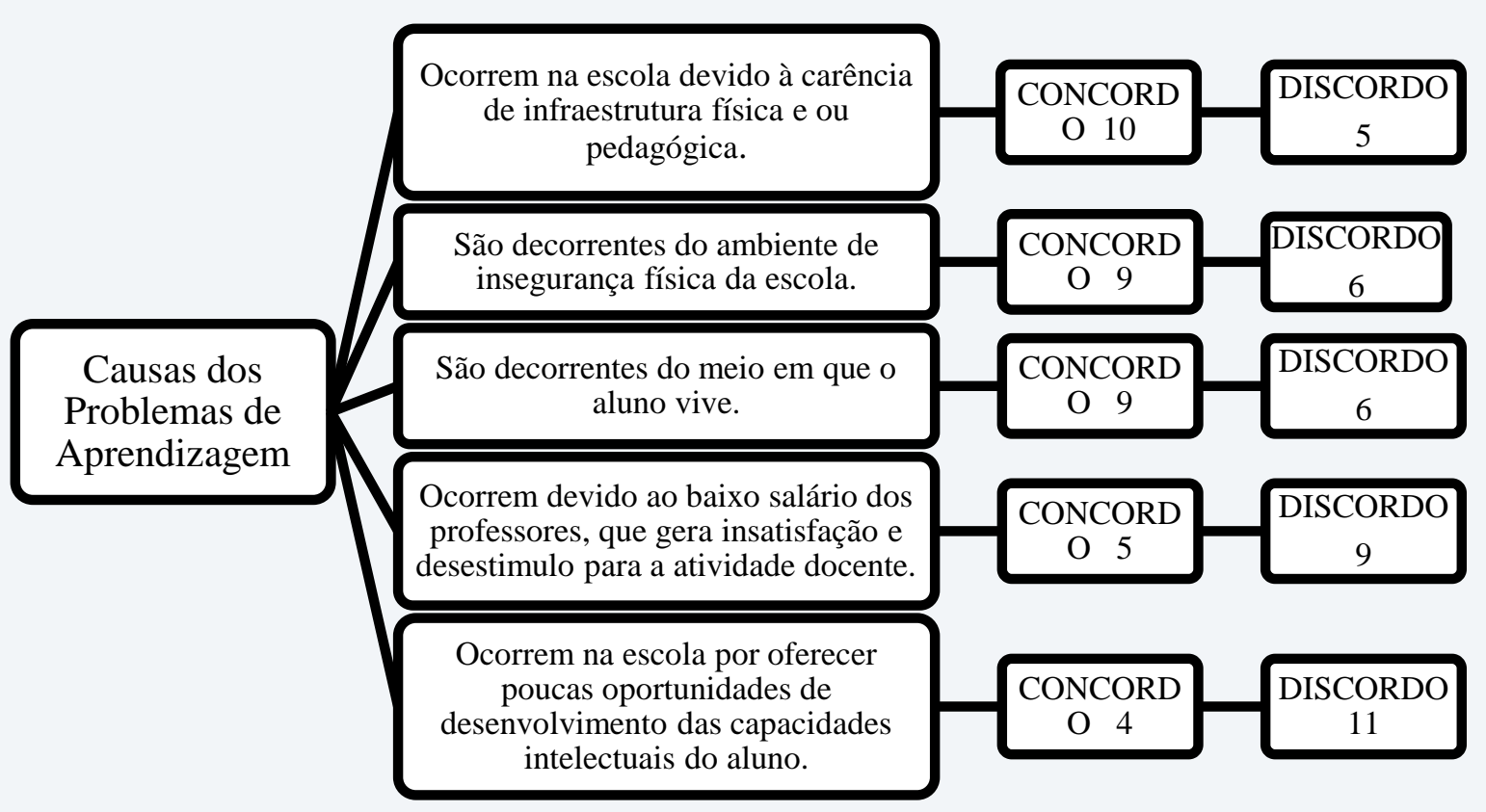


Percebemos que na pesquisa, os professores acreditam que os problemas decorrentes na aprendizagem dos alunos, estão diretamente relacionados a falta de uma estrutura adequada física e pedagógica, da insegurança física no interior do ambiente assim como do meio em que a aluno vive. Além desses outros que aparecem com menos frequência são: o baixo salário dos professores decorrentes da falta de valorização profissional e segundo os entrevistados as poucas oportunidades que a escola oferece que possibilitem desenvolver as capacidades intelectuais dos aluno.

Lembramos que quanto a este último item, a escola tem presente os programas: PME e ProEMI, atendendo o ensino fundamental e ensino médio que é seu público alvo, no entanto, os professores não citam esses programas como parte das atividades da escola, inclusive quando perguntados anteriormente se conjugavam suas atividades de sala de aula com as atividades no contra turno nenhum dos entrevistados respondeu que fazia essa conexão. É como se fosse algo a parte do processo de apropriação do conhecimento por parte dos alunos. Percebemos que as atividades no contra turno possibilitadas programas de fomento a educação integral que buscam melhorias na qualidade de ensino estão dissociadas do ensino formal na sala de e pela pesquisa percebemos que estas ações de intervenção não são reconhecidas enquanto ações complementares que visam tornar o ensino significativo para o aluno. Moll nos alerta para a implementação de programas a um curto período que teoricamente alteram tempo e espaço na escolas pois:

Nenhuma escola construída como "escola de turno", com espaços
delimitados para determinado número de estudantes para a manhã, para a
atarde, e às vezes para os três turnos diários, "transforma-se", de um dia para
o outro, em escola de jornada ampliada, em que a escola inclui várias
refeições diárias, em escola que acompanha, qualifica e diversifica a
experiência formativa de seus estudantes (2012, p.138).

Aliado aos aspectos ressaltados por Moll, constata-se também pelos relatos das características metodológicas apresentadas, que apesar de um nível amplo de conhecimento técnico por parte dos docentes que são todos graduados na área específica que atuam, quando se trata de metodologias que a maioria das instrumentos, técnicas e estratégias didáticas utilizadas pelos professores na sala de aula limitam e algumas vezes como é o caso da exposição oral não permite ou não incentiva a participação dos alunos.

Não obstante, Saviani nos previne para a importância de atentarmos sobre a escolha nos métodos de ensino pois: 
Serão métodos que estimularão a atividade e iniciativa de alunos sem abrir mão, porém, da iniciativa do professor; favorecerão o diálogo dos alunos entre si e com o professor, mas sem deixar de valorizar o diálogo com a cultura acumulada historicamente; levarão em conta os interesses dos alunos, os ritmos de aprendizagem e o desenvolvimento psicológico, mas sem perder de vista a sistematização lógica dos conhecimentos, sua ordenação e gradação para efeitos do processo de transmissão-assimilação dos conteúdos cognitivos (2008, p.69).

Nesse diálogo fica latente a importância da escola de métodos de ensino que enriqueça, o desenvolvimento integral do aluno em seus aspectos físicos, biológicos, cognitivos, emocionais, sociais dentre outros que são fundamentais na construção de ser humano autônomo, criativo, crítico e reflexivo.

\section{Considerações finais}

A educação integral em tempo integral enquanto política pública desenvolvida nas escolas de educação básica, é vislumbrada como potencial benéfico no processo ensino aprendizagem nas instituições escolares no sentido de desenvolvimento de atividades complementares que venham a somar a educação que acontece dentro da sala de aula.

É importante frisar que muitos aspectos precisam ser explorados, discutidos e analisados quando se pondera sobre as experiências que as escolas empenharam-se em realizar no que diz respeito a educação integral em tempo integral.

Percebemos que a política não é assumida efetivamente pela comunidade escolar seja por desconhecimento, seja por falta de estrutura, de informação/formação e até mesmo participação na opção de realizar ou não os programas nas escolas.

A efetivação da política depende de fatores como: infraestrutura, adequação de tempo e espaços na organização do trabalho pedagógico, formação para compreender e assumir o compromisso de trabalhar com o objetivo definido de realizar a educação integral não somente por parte dos professores como também e principalmente pelos outros sujeitos da comunidade escolar que ficam alheios as ações que acontecem na escola, metodologias alinhadas ao processo e continua reflexão da prática pedagógica desenvolvida no cotidiano da escola.

No entanto, não podemos deixar de reconhecer que as tentativas e/ou experiências encontradas nas escolas que assumiram a proposta, alteraram a rotina das mesmas que buscaram estudar, conhecer e desenvolver ações, embora de maneira tímida ou arrojadas, que pudessem ir além dos conteúdos transmitidos em sala de aula. 


\section{REFERÊNCIAS}

BRASIL, Lei no 13.415, de 16 de fevereiro de 2017. Disponível em: < http://www.planalto.gov.br/ccivil_03/_ato2015-2018/2017/lei/113415.htm> Acesso em: 01.06.2018.

BRASIL, Medida Provisória n 746/206 de 22 de setembro de 2016. Disponível em: < http://www2.camara.leg.br/legin/fed/medpro/2016/medidaprovisoria-746-22-setembro-2016783654-publicacaooriginal-151123-pe.html> Acesso em: 01.06.2018.

BRASIL, Portaria no 727, de 13 de junho de 2017. Disponível em:< http://www.fnde.gov.br/acesso-a-informacao/institucional/legislacao/item/10931-portariamec-n\%C2\%BA-727,-de-13-de-maio-de-2017>. Acesso em: 08.06.2018.

CAVAliERE, A. M. Tempo de escola e Qualidade na Educação Pública. Educ. Soc., Campinas, vol. 28, n.100 - Especial, p. 1015-1035, out. 2007. Disponível em <http://www.cedes.unicamp.br>. Acesso em: 13.09.2017.

FONSECA, W.D.(1919-2010) Santarém Momentos Históricos - ICBS - Instituto Cultural Boanerges Sena - Santarém, 2015, p.240.

GADOTTI, M. Educação Integral no Brasil: inovações em Processo. São Paulo: Editora e Livraria Instituto Paulo Freire, 2009.

GOMES, T. C.; COLARES, M. L. I. S. A Educação Integral e o Programa Ensino Médio Inovador - PROEMI. 1. Ed. - Curitiba, Pr :CRV, 2018. 158p.

GUARÁ, I. M. F. Rosa. É imprescindível educar integralmente. Cadernos CENPEC, 2006, $\mathrm{n}^{\circ} 2$.

MAURÍCIO, Lúcia Velloso. Políticas públicas, temo, escola. In: Educação Integral em tempo integral: estudos e experiências em processo. Lígia Martha C. da Costa Coelho (org.). Petrópolis, RJ: DP et Alii; Rio de Janeiro: FAPERJ, 2009.

MOLL, J. A agenda da educação integral: Compromissos para sua consolidação como política pública. In: MOLL, Jaqueline et al. Caminhos da educação integral no Brasil: direitos a outros tempos e espaços educativos. Porto Alegre: Penso, 2012, p. 129-146.

O MANIFESTO DOS PIONEIROS DA EDUCAÇÃO NOVA (1932). Disponível em:< http://www.histedbr.fe.unicamp.br/revista/edicoes/22e/doc1_22e.pdf >. Acesso em: 23.06.2018.

ORSO, José Paulino. As possibilidades e os limites da educação na sociedade de classes In: ORSO, P.J.; GONÇALVES, S.R.; MATTOS, V. M.de. Educação e Sociedade de Classes. Editora Expressão Popular,2008.

PROGRAMA NACIONAL DE COOPERAÇÃO ACADÊMICA-EDITAL No 071/2013 PROCAD/CAPES. 
SAVIANI, D. Escola e democracia. 40.ed. - Campinas, SP: Autores Associados,2008 (Coleção Polêmicas do Nosso Tempo; vol. 5).

UFOPA: Histórico e Localização. Disponível em:

<http://www.ufopa.edu.br/ufopa/institucional/sobre-a-ufopa/historico-e-localizacao/>. Acesso em 01.08.2018.

\section{SOBRE AS AUTORAS:}

\section{Tânia Castro Gomes}

Mestra em Educação pela Universidade Federal do Oeste do Pará (UFOPA). Integrante do Projeto: "As Experiências Pedagógicas das Políticas de Educação Integral na Amazônia: Rede de Pesquisa e Formação Acadêmica", UNICAMP/UNIR/UFOPA, Programa Nacional de Cooperação Acadêmica (PROCAD)-Edital nº 071/2013. Membro do Grupo de Estudos e Pesquisas "História, Sociedade e Educação no Brasil", HISTEDBR/UFOPA. E-mail: tcastrogomes@bol.com.br

\section{Maria Lília Imbiriba Sousa Colares}

Doutora e Pós-doutora em Educação pela Universidade Estadual de Campinas (UNICAMP). Docente do Programa de Pós-graduação em Educação da Universidade Federal do Oeste do Pará (UFOPA). Coordenadora Associada II do Projeto: "As Experiências Pedagógicas das Políticas de Educação Integral na Amazônia: Rede de Pesquisa e Formação Acadêmica", UNICAMP/UNIR/UFOPA, Programa Nacional de Cooperação Acadêmica (PROCAD)-Edital no 071/2013. Líder Adjunta do Grupo de Estudos e Pesquisas "História, Sociedade e Educação no Brasil”, HISTEDBR/UFOPA. E-mail: maria.colares@ ufopa.edu.br 